\title{
Árboles del Valle Central de Costa Rica: reproducción de guanacaste (Enterolobium cyclocarpum (Jacq.) Griseb.).
}

\section{Trees of the Central Valley of Costa Rica: reproduction guanacaste (Enterolobium cyclocarpum (Jacq.) Griseb.).}

\author{
Freddy Rojas-Rodríguez ${ }^{1}$ (D) - Gustavo Torres-Córdoba²
}

\begin{abstract}
The following issue presents a brief description about the guanacaste (Enterolobium cyclocarpum (Jacq.) Griseb.), tree, including information about its phenology which directly relates to fruit recollection, seed treatment, nursery, and germination processes.
\end{abstract}

Keywords: Phenology, seeds treatments, management at nursery, germination, trees.

\section{Resumen}

Se presenta una breve descripción del árbol "guanacaste" (Enterolobium cyclocarpum (Jacq.) Griseb.), información sobre fenología como base para la recolección de frutos, el manejo de las semillas, la viverización y el proceso de germinación.

Palabras clave: Fenología, manejo de semillas, viverización, germinación, árboles. 


\section{Taxonomía}

Nombre científico: Enterolobium cyclocarpum (Jacq.) Griseb.

Nombre común: Guanacaste.

Familia: Fabaceae-Mimosaceae.

Origen: Nativa.

Distribución en el mundo: Desde México hasta Venezuela.

Distribución en Costa Rica: En la Vertiente Pacífica. Se adapta a climas con precipitaciones entre 750 y 2500 $\mathrm{mm} / \mathrm{año}$; temperaturas entre 23 y $30^{\circ} \mathrm{C}$ y a un rango altitudinal entre los 0 y $1200 \mathrm{msnm}$.

\section{Descripción}

Árbol grande, caducifolio, de copa extendida con ramas ascendentes y forma semiesférica.

El fuste es de hasta $50 \mathrm{~m}$ de altura y $3 \mathrm{~m}$ de diámetro, robusto, cilíndrico y con gambas pequeñas.

La corteza es lisa a ligeramente fisurada de color gris claro a blancuzco, con gran cantidad de lenticelas, con un exudado pegajoso de sabor dulce que coagula al contacto con el aire.

Las hojas se componen de 1 a 9 pares de pinnas, y estas de 15 a 30 pares de foliolos, de 9-15 x 2-24 mm [1].

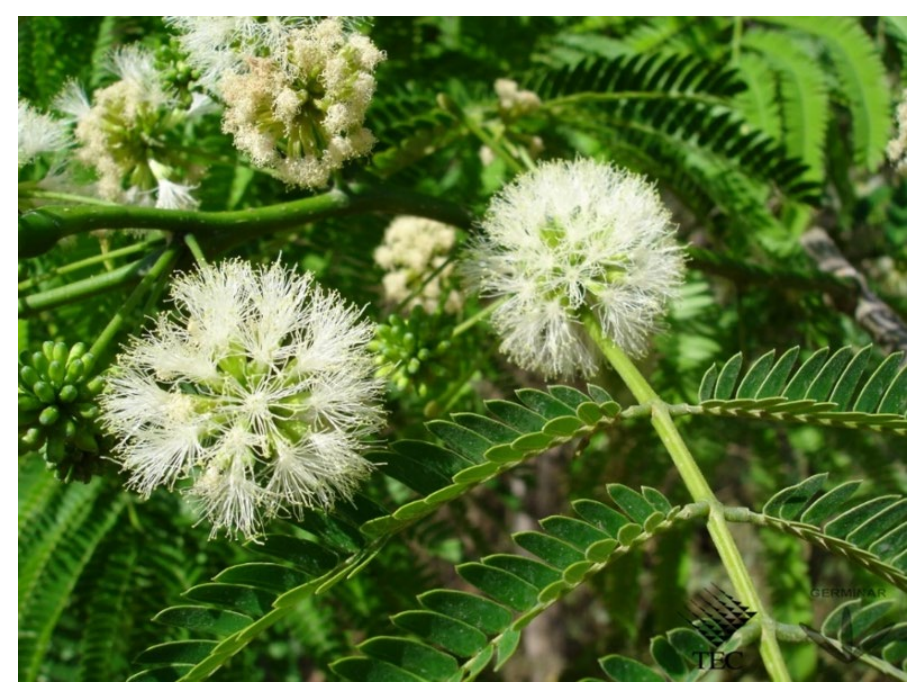

Figura 1. Flores y hojas de guanacaste.

Figure 1. Flower and leaves of "guanacaste" tree.
Son de color verde pálido y haz verde oscuro, con una glándula cerca de la base.

Las flores son cabezuelas axilares, con flores pequeñas, sésiles, de color blancuzco a verde claro. Cáliz densamente pubescente, corola blancuzca, fragantes y visitada por abejas.

El nombre guanacaste es un nahuatlismo derivado de "cuaútl", árbol y "nacaztli", oreja y se refiere a la forma del fruto [1]. Estos son secos, tipo vaina indehiscente, enroscados, leñosos, lustrosos, glabros, de color café oscuro cuando maduros, conteniendo de 10 a 15 semillas semejantes a una oreja humana (de ahí el nombre Kurú) [2].

Las semillas son comprimidas, brillantes, cafés, de 1,5 a $2 \mathrm{~cm}$ de largo, testa dura y resistente, ortodoxas, pleurograma prominente (línea pálida concéntrica que sigue el contorno) [2].

\section{Dendrofenocronograma}

Se presenta a continuación información fenológica de guanacaste para el Valle Central de Costa Rica.

\section{Manejo de semilla y viverización}

Los frutos de guanacaste se recolectan en los meses de febrero, marzo, abril y mayo en la región del Valle Central de Costa Rica. La madurez de estos se reconoce por su color café siendo su dispersión barócora (caen por su propio peso). Su recolección, fácilmente se hace directo del suelo. El empleo de una máquina chancadora ha resultado ser la mejor técnica para la extracción mecanizada de las semillas; también se hace, para pocas cantidades, de forma manual con el uso de tijeras podadoras.

Cuadro 1. Dendrofenocronograma de guanacaste en el Valle Central, Costa Rica.

Table 1. Tree phenology through time in "guanacaste" in Central Valley, Costa Rica

\begin{tabular}{|c|c|c|c|c|c|c|c|c|c|c|c|c|}
\hline \multirow{2}{*}{ Características } & \multicolumn{12}{|c|}{ Meses del año } \\
\hline & E & $\mathrm{F}$ & M & A & M & $\mathrm{J}$ & J & A & $\mathrm{s}$ & o & $\mathrm{N}$ & D \\
\hline \multicolumn{13}{|l|}{ Hojas } \\
\hline Flores & & & & & & & & & & & & \\
\hline Frutos verdes & & & & & & & & & & & & \\
\hline Frutos maduros & & & & & & & & & & & & \\
\hline
\end{tabular}




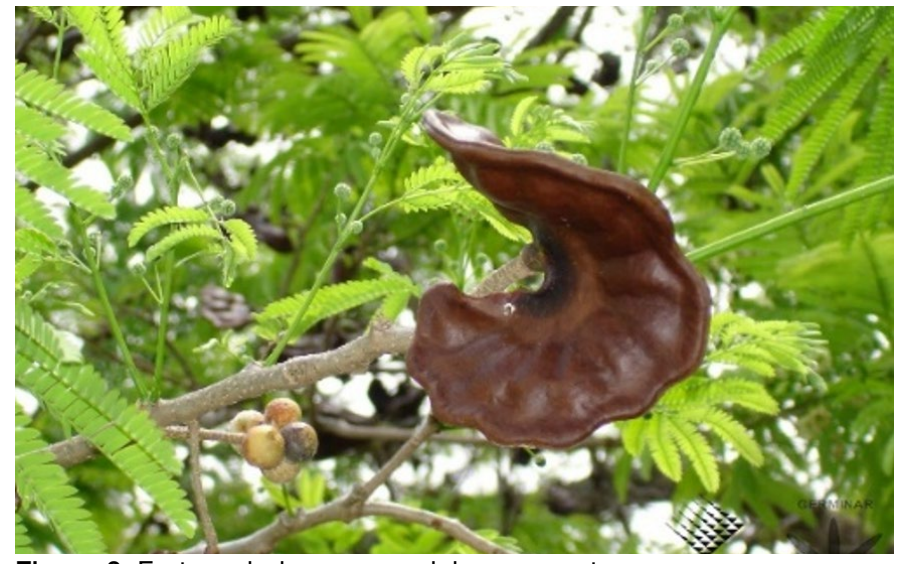

Figura 2. Frutos y hojas nuevas del guanacaste.

Figure 2. Fruits and leaves of "guanacaste" tree.

Una vez liberadas las semillas, estas pueden ser almacenadas por un período de 3 a 12 meses, idealmente en condición de cuarto frío, a una temperatura de 3 - 10 ${ }^{\circ} \mathrm{C}$ y una humedad relativa de $10 \%$ y en bolsas selladas herméticamente [2].

Como tratamiento pregerminativo, el uso de potasa diluida en agua es efectivo cuando la semilla es inmersa en una solución de este químico con agua durante 20 minutos. Posteriormente deben ser lavadas y colocadas en agua durante 24 horas antes de su siembra. Sin embargo, un método menos riesgoso es la incisión con el uso de un cortauñas en el extremo de la semilla (cerca de donde se ubica el embrión); posteriormente la semilla es inmersa en agua al menos durante 8 horas antes de su siembra [2].

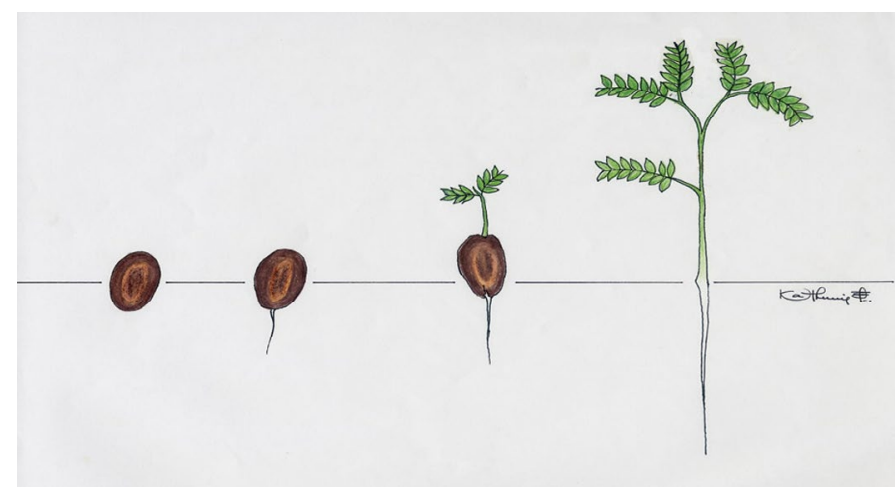

Figure 3. Proceso de germinación de guanacaste.

Figure 3. Seed germination of "guanacaste" tree.
Las semillas se siembran por el método de puntos en un almácigo o cama de germinación, o bien directamente en el sistema de producción (bolsa o contenedor), en un sustrato a base de tierra más arena en una relación 2:1, respectivamente. Éstas se deben cubrir apenas superficialmente, siendo que la germinación se experimenta entre 12-21 días después de la siembra. La germinación, dependiendo de la calidad de la semilla, varía de un $85-100 \%$ y se puede llegar a obtener un total de 1225 semillas por kilo [2].

Las plántulas se encuentran listas para su repique o trasplante, bajo el sistema de producción en bolsa plástica o contenedor, una semana posterior a la germinación. Para su mantenimiento, es recomendable aplicar sombra por un periodo no mayor a los 8 días, así como fertilización química u orgánica, de preferencia, en caso requerido [2].

\section{Proceso de germinación}

El tipo de germinación del guanacaste es epígea, según la figura 3.

\section{Referencias}

[1] León, J. y Poveda, L. (2000). Los nombres comunes de las plantas en Costa Rica. (Ed.) Pablo Sanchez. Editorial Guayacán: San José, Costa Rica

[2] Torres, C., Carvajal, D., Rojas, F. y Arguedas M. (2011). Reproducción de especies arbóreas y arbustivas de la región central de Costa Rica (Germinar 2.0). Cartago, Costa Rica: Instituto Tecnológico de Costa Rica. Recuperado de: https://www.tec.ac.cr/sites/default/files/media/swf/ Germinar_2/Germinar-2.swf 